\title{
Psychosocial reintegration following traumatic spinal cord injury in South Africa: The influence of employment, injury characteristics and living situation
}

\section{Eugene Nizeyimana, Joliana Phillips \& Conran Joseph}

To cite this article: Eugene Nizeyimana, Joliana Phillips \& Conran Joseph (2022): Psychosocial reintegration following traumatic spinal cord injury in South Africa: The influence of employment, injury characteristics and living situation, The Journal of Spinal Cord Medicine, DOI:

10.1080/10790268.2021.2016306

To link to this article: https://doi.org/10.1080/10790268.2021.2016306

\section{曲 Published online: 10 Jan 2022.}

\section{Submit your article to this journal ש}

\section{Џ Article views: 27}

Q View related articles $\square$

View Crossmark data ऍ 
Psychosocial reintegration following traumatic spinal cord injury in South Africa: The influence of employment, injury characteristics
and living situation

\section{Eugene Nizeyimana $\oplus^{1}$, Joliana Phillips $\oplus^{2}$, Conran Joseph $\odot^{1}$}

${ }^{1}$ Department of Health and Rehabilitation Sciences, Division of Physiotherapy, Stellenbosch University, Cape Town, South Africa, ${ }^{2}$ Department of Physiotherapy, University of the Western Cape, Cape Town, South Africa

Objectives: To determine the influence of employment, injury characteristics and living situation on psychosocial reintegration in individuals who sustained a traumatic spinal cord injury (TSCI) in South Africa.

Design: A cross-sectional exploratory survey.

Settings: Communities of the Cape Metropolitan Area, South Africa.

Participants: A total of 108 community- dwelling adults, between ages of 19 and 71 years, who have sustained a TSCI more than 1- year ago.

Outcome measures: : The Sydney psychosocial reintegration scale (SPRS-2).

Results: The SPRS-2 and domains mean (SD) scores were: (1) Overall SPRS-2 of 27.87(13.4); (2) Occupational activity of 8.62 (4.8); (3) Interpersonal relationships of 9.80 (5.1); and (4) Living skills of 9.45 (4.9). Multivariate regression analysis resulted in two significant independent variables, namely employment and living situation. Employment alone explained $24.3 \%$ of the variance in the overall psychosocial model, $25.6 \%$ in the occupational activity model, while employment together with living situation explained $24.2 \%$ of the variance in the living skills model, with those employed reporting better psychosocial reintegration and those living in informal dwellings reporting poorer psychosocial reintegration.

Conclusion: Employment and living situation strongly influenced psychosocial reintegration following a TSCI, indicating the important role of socio-economic status for psychosocial adaptation after injury. As employment plays a significant mediating role, and living in informal dwellings negatively affect psychosocial reintegration following a TSCl, rehabilitation stakeholders and policy makers need to continue lobbying for social and political change that support employment opportunities and provide accessible housing for persons with TSCl.

Keywords: Employment, Injury characteristics, Living situation, Psychosocial reintegration, Spinal cord injury, South Africa

\section{Introduction}

Traumatic spinal cord injury (TSCI) is a complex health condition that can have a significant negative effect on the physical and psychosocial functioning of survivors. ${ }^{1}$ The lived experience of people with a TSCI is most commonly expressed in terms of the impact on their community and social engagement. Therefore, the importance of rehabilitation practice following a TSCI is evident in its philosophy to treat beyond impairment and physical function, but rather to help

Correspondence to: Eugene Nizeyimana, Department of Health and Rehabilitation Sciences, Division of Physiotherapy, Stellenbosch University, Cape Town, South Africa. Email: nizegene@gmail.com a person to reach his or her fullest physical and psychosocial functioning. ${ }^{2-6}$

The degree to which a person with a disability is wellintegrated into society is a complex phenomenon that is influenced by many factors, including (1) the consequences of the injury such as secondary health complications, (2) an individual's characteristics such as demographics, and (3) environmental factors including physical, social, attitudinal as well as cultural issues. ${ }^{3,7,8}$ Despite the fact that some demographic factors are not likely modifiable through rehabilitation, their role in community reintegration should be understood before 
other influences on community reintegration are examined. ${ }^{3}$

The assessment of community reintegration is not straightforward as "subjective versus objective" approaches at the measurement may imply. For example, one instrument may look at the quantity or frequency of outings, whereas another may consider the quality and subjective enjoyment of such outings. ${ }^{6}$ This means that interested stakeholders, such as clinicians, researchers and policymakers, should have clarity on the desired construct and nature of community reintegration to ensure that recommendations are geared towards improving subjective versus objective community reintegration.

Various instruments have been previously used to capture the quantitative aspect of community reintegration., The Craig Handicap Assessment and Reporting Technique (CHART) is a well-established outcome measure for people with SCI that has been preferred by various researchers. The CHART quantifies the degree to which impairments and disabilities result in functioning in the years after initial rehabilitation. ${ }^{9}$ Although the CHART is a good instrument to assess the aspect of quantitative community reintegration, it does not inform us about qualitative aspects of community reintegration. ${ }^{6}$ To address this limitation, the Sydney Psychosocial Reintegration Scale (SPRS-2) was created to measure qualitative as opposed to quantitative features. For instance, the social dimension of the CHART quantifies the number of social contacts, while the relationships domain of the SPRS-2 addresses the quality of relationships. The occupation dimension of CHART quantifies the number of hours spent at work while the SPRS-2 addresses the quality of hours spent at work. ${ }^{6}$ Therefore, the SPRS-2 might provide researchers an option to evaluate community reintegration from a qualitative perspective.

Although previous studies investigated community reintegration and factors influencing it following disabilities in South Africa, ${ }^{10-12}$ none of them was focused on TSCI. Furthermore, none of these studies used SPRS-2 to assess qualitative aspect of psychosocial reintegration that could provide valuable insights on how reintegration is perceived and how it could be improved. Thus, the main aim of this study was to assess experienced quality of psychosocial reintegration and determine the influence of employment, injury related characteristics and living situation among individuals who have sustained a TSCI in South Africa.

\section{Materials and methods Study design}

A cross-sectional exploratory survey was conducted on individuals with a TSCI who lived in the community.

\section{Setting}

The study was conducted in the Cape Metropolitan Area that is situated in the Western Cape Province of South Africa with a population of approximately 3.7 million people. The Cape Metropole was chosen because of its ethnic diversity that includes persons of black African, white, and mixed race. The catchment area is one of the largest in the country, including both urban and peri-urban settings.

\section{Participants}

The Western Cape Quad-Para Association of South Africa (QASA) has a database of persons with TSCI, and this was used as the target population. Individuals with a SCI are supported by QASA, an organization that has offices in several of the country's provinces. All individuals with a TSCI $(N=300)$ registered under QASA database in the Western Cape were contacted via email for participation. Seventy five $(75 \%)$ of those on the QASA's registry were males, with about $60 \%$ below the age of 40 years old. Inclusion criteria for the study were: (1) aged 18 years old and above; (2) had sustained a TSCI; (3) were living with a TSCI at least oneyear post-injury; and (4) residing in communities. A oneyear post injury time frame was selected since clients with SCI have typically completed institutionalized care and rehabilitation and made a transition to their immediate home and community life. Furthermore, this timeframe would have allowed for sufficient engagement with the immediate environment and assessment of challenges.

\section{Procedure}

In line with the South African Protection of Personal Information (POPI) Act (No 4 of 2013), ${ }^{13}$ the organization (QASA) sent out e-mail invitations, information sheet outlining the purpose of the study, the questionnaire, and a consent form to registered individuals with a TSCI. The researcher's contact details (telephone numbers and email address) were included on the information sheet, should the need arise for participants to make contact. Participants returned their signed consent forms and completed questionnaire directly to the researcher via email.

A total of 112 participants consented to participate in the study. However, four (4) participants were excluded for the following reasons: (1) younger than 18 years of age $(n=1),(2)$ lived in the in the community for less 
than one-year after the injury $(n=1)$, and (3) non-traumatic SCI $(n=2)$. Thus, 108 met the inclusion criteria and were included in the study, yielding a response rate of $36 \%$.

\section{Instrument}

Data were collected with self-administered questionnaire that included the following sections: (1) Demographic and Injury Characteristics Questionnaire, (2) the Sydney Psychosocial Reintegration Scale (PSRS-2).

\section{Demographic and injury characteristics questionnaire (predictor variables)}

This consisted of ten (10) items designed to elicit specific demographic and injury characteristics about the participants, including age, sex, race, marital status, level of education, living situation, employment status, level of the injury, cause of injury and time living with SCI. Participants were asked to tick a statement that best corresponds with their answers.

\section{The Sydney psychosocial reintegration scale (SPRS-2) (outcome variables)}

The SPRS-2 was initially designed with questions to measure psychosocial reintegration after traumatic brain injury (TBI) targeting three domains: (1) occupational activity (OA), e.g. "how do you rate your work/study skills" and "how do you rate the number or type of leisure activities or interests"; (2) interpersonal relationships (IR) e.g. "how do you rate your relationship with other family members" and "if you have a spouse/partner, how do you rate your relationship"; (3) living skills (LS), e.g. "how do you rate your living situation" and "how do you rate your social skills". ${ }^{2}$ Scores range from $0-16$ for each domain and 0-48 for SPRS-2 overall score. For domain and overall scores, a higher score indicates better psychosocial reintegration.

Although SPRS-2 was initially developed to measure psychosocial reintegration after TBI, its reliability, validity and sensitivity to change in people with SCI have been tested in comparison to CHART, and it has shown to be an instrument with greater sensitivity to change with overall less ceiling effects compared to CHART. ${ }^{6}$ The internal consistency was measured in this study and the Cronbach alpha was 0.94. Thus, SPRS-2 demonstrated to be reliable and easy to administer.

In this particular study, the occupational activity domain measured the quality of hours participants spent at work or organizing other physical activity, and the interpersonal relationship domain measured the quality of relationships participants had with their significant others, while the living skills domain measured the quality of independent living skills of the participants.

\section{Data analysis}

Data was analysed with the Statistical Package for Social Sciences (SPSS) Version 26. Demographic and injury characteristics data were summarized with the use of descriptive statistics and presented in a frequency table with percentages, means, and standard deviations. Bivariate linear regression analysis (T-tests and oneway analysis of variance with post-hoc comparison) was performed to examine the relationships between the dependent/outcome variables (SPRS-2 total score and scores of each domain), and each independent/predictor variable (demographic and injury characteristics). Level of significance was set at $\mathrm{P} \leq .05$. Variables significantly associated with psychosocial reintegration in bivariate analysis, followed by an evaluation of collinearity, were included in multiple linear regression analyses. Dummy variables were created for all categorical independent variables prior to multiple regression analysis, and relevant reference categories were selected. A model predicting general psychosocial reintegration after sustaining a TSCI was obtained by multiple regression analysis following a backwards selection procedure. The final analysis included the development of three-regression models that were conducted to determine demographic and injury characteristics that affect each domain of psychosocial reintegration.

\section{Results}

General characteristics of the study sample $(n=$ 108)

Table 1 presents general characteristics of the study sample. The study sample included individuals with a TSCI $(n=108)$ between the ages of $19-71$ years $(M=$ $37.2 ; \mathrm{SD}=12.2$ ), living in a community of the Cape Metropolitan Area, South Africa. The time since injury ranged between 1 and 35 years $(M=10.24$; $\mathrm{SD}=9.1)$. Males formed the majority of the study sample $(78 \%)$, one third were employed $(38 \%)$ and approximately one-quarter $(27 \%)$ were living in informal dwellings/shacks. More than half of the participants $(58.3 \%)$ were classified as paraplegic, while the cause of injury was primarily motor vehicle accidents (43.5\%), followed by violence-related causes $(38 \%)$.

The SPRS-2 and domains mean (SD) scores were: (1) Overall SPRS-2 of 27.87(13.4); (2) Occupational activity of 8.62 (4.8); (3) Interpersonal relationships of 9.80 (5.1); and (4) Living skills of 9.45 (4.9). 
Table 1 General characteristics of the study sample $(n=108)$.

\begin{tabular}{|c|c|}
\hline Variables. & Frequency (\%). \\
\hline \multicolumn{2}{|l|}{ Age Group } \\
\hline $15-30$ & $30(27.8)$ \\
\hline $31-45$ & $50(46.3)$ \\
\hline $46+$ & $28(25.9)$ \\
\hline \multicolumn{2}{|l|}{ Sex } \\
\hline Male & $84(77.8)$ \\
\hline Female & $24(22.2)$ \\
\hline \multicolumn{2}{|l|}{ Level of Injury } \\
\hline Paraplegia & $63(58.3)$ \\
\hline Tetra/Quadriplegia & $45(41.3)$ \\
\hline \multicolumn{2}{|l|}{ Time Living with SCI (years) } \\
\hline $1-5$ & $54(50.0)$ \\
\hline $6-10$ & $13(12.0)$ \\
\hline $11-15$ & $17(15.7)$ \\
\hline 16 and above & $24(22.2)$ \\
\hline \multicolumn{2}{|l|}{ Race } \\
\hline Black & $49(45.4)$ \\
\hline Mixed race & $32(29.6)$ \\
\hline White & $27(25.0)$ \\
\hline \multicolumn{2}{|l|}{ Marital Status } \\
\hline Single & $88(81.5)$ \\
\hline Married & $20(18.5)$ \\
\hline \multicolumn{2}{|l|}{ Employment Status } \\
\hline Employed & $41(38.0)$ \\
\hline Unemployed & $67(62.0)$ \\
\hline \multicolumn{2}{|l|}{ Education Level } \\
\hline Below Matric & $19(17.6)$ \\
\hline Completed Matric & $65(60.2)$ \\
\hline Tertiary & $24(22.2)$ \\
\hline \multicolumn{2}{|l|}{ Accommodation } \\
\hline House & $50(46.3)$ \\
\hline Nursing Home & $29(26.9)$ \\
\hline Informal Dwelling/ Shack & $29(26.9)$ \\
\hline
\end{tabular}

Bivariate linear regression analysis of demographic and injury characteristics influencing psychosocial reintegration

The relationship between demographic, injury characteristics and overall SPRS-2, as well as associated domains (OA, IR, LS), were examined using bivariate linear regression analysis and the results are presented in Table 2. Race, education, employment, and living situation were significantly associated with the overall SPRS-2 and all three domains. Additionally, age was significantly associated with overall SPRS-2, OA, and LS. There was no statistically significant difference between injury characteristics, SPRS-2, and all associated domains.

Multivariate regression analysis of overall SPRS2 and individual domains

From variables that proved to be statistically significant in bivariate linear regression at the $\mathrm{P}$ value of $<0.05$, standard multiple regression models were computed to determine independently associated factors of overall psychosocial reintegration (total SPRS-2) and its three separate domains (OA, IR, and LS). The results of the models are presented in Table 3 . Employment alone explained $24.3 \%$ of the variance in the overall SPRS-2 (Standardized coefficient $=.258$, $\mathrm{P}<.003$ ), and $25.6 \%$ of the variance in $\mathrm{OA}$ (Standardized coefficient $=.264, \quad \mathrm{P}<.001$ ), with those who were employed reported better psychosocial reintegration compared to those unemployed. In the LS domain, employment and living situation together explained $24.2 \%$ of the variance in the model while employed participants reported better reintegration: standardized coefficient $=.190, \mathrm{P}=.045$ and those living in the informal dwelling/shacks reported reintegration to a lesser degree: standardized coefficient $=-$. $243, \mathrm{P}=.040$ compared to those that were living in the formal houses/regular and nursing homes.

\section{Discussion}

To the best of our knowledge, this is the first study to assess psychosocial reintegration using the SPRS-2 in persons who have sustained a TSCI in South Africa. In this study, employment status and living situation were found to be significant factors influencing psychosocial reintegration among persons with a TSCI in South Africa, of which being employed was significantly associated with better psychosocial reintegration, while living in informal dwelling/shacks was significantly associated with poorer psychosocial reintegration.

The results of our study are consistent with the existing literature. Leach et al. ${ }^{14}$ are of the view that employment is the foundation of social inclusion for both ablebodied and disabled individuals. According to Ullah et al.,${ }^{15}$ being employed after SCI helps re-develop a sense of self, re-establishing place in the community, and regaining economic self-sufficiency. A study conducted in Canada $^{16}$ reported that individuals with SCI had a strong desire to be productive in search of better lives after the injury. Miller et al. ${ }^{17}$ also reported that hours of paid labor were positively associated with interacting with others and completing tasks.

On the basis of our results, and existing literature, we can conclude that the level of involvement in various activities such as work and leisure activities influence one's satisfaction on his/her psychosocial reintegration.

The employment rate of $38 \%$ reported in this study is higher than the recently reported employment rate of $28.5 \%$ in South Africa for individuals with SCI. ${ }^{18}$ The variation between employment rate in this study and that previously reported in South Africa could be attributed to the method of data collection. Both studies used non-probability sampling technique. As this is a convenient sampling technique, some members of the population are most likely to be 
Table 2 Bivariate linear regression analysis results of overall SPRS-2, individual domain scores with general characteristics of the study sample.

\begin{tabular}{|c|c|c|c|c|c|c|c|c|}
\hline Variables & $\begin{array}{c}\text { SPRS-2 } \\
\text { Mean(SD) }\end{array}$ & $\begin{array}{c}P \\
\text { value }\end{array}$ & $\begin{array}{c}\text { OA } \\
\text { Mean(SD) }\end{array}$ & $\begin{array}{c}P \\
\text { value }\end{array}$ & $\begin{array}{c}\text { IR } \\
\text { Mean(SD) }\end{array}$ & $\begin{array}{c}P \\
\text { value }\end{array}$ & $\begin{array}{c}\text { LS } \\
\text { Mean(SD) }\end{array}$ & $\begin{array}{c}P \\
\text { value }\end{array}$ \\
\hline Age Group* & & $.006^{\dagger}$ & & $.009^{\dagger}$ & & 130 & & $.002^{\dagger}$ \\
\hline $15-30$ & 22.33(11.3) & & $6.57(4.5)$ & & $8.70(5.0)$ & & $7.07(4.2)$ & \\
\hline $31-45$ & $28.16(13.8)$ & & $8.86(5.0)$ & & $9.56(5.3)$ & & $9.74(5.1)^{\star}$ & \\
\hline $46+{ }^{*}$ & $33.29(11.7)^{\star}$ & & $10.39(4.3)^{\star}$ & & $11.39(5.1)$ & & $11.50(4.2)^{*}$ & \\
\hline Sex & & .132 & & .203 & & .212 & & .137 \\
\hline Male & $28.90(13.5)$ & & $8.94(4.8)$ & & $10.13(5.4)$ & & $9.83(4.5)$ & \\
\hline Female & $24.25(12.4)$ & & $7.50(5.3)$ & & $8.63(4.5)$ & & $8.13(4.3)$ & \\
\hline Race $^{*}$ & & $.001^{\dagger}$ & & $.000^{\ddagger}$ & & $.008^{\dagger}$ & & $.011^{\dagger}$ \\
\hline Black & 23.08(12.6) & & $6.88(4.5)$ & & $8.24(5.3)$ & & $7.96(5.1)$ & \\
\hline Mixed race & $29.31(14.5)$ & & $8.72(5.1)$ & & $10.38(5.6)$ & & $10.22(5.3)$ & \\
\hline White* & $34.85(9.7)^{*}$ & & $11.67(3.9)^{*}$ & & $11.93(3.7)^{*}$ & & $11.26(3.7)^{*}$ & \\
\hline Education Level* & & $.008^{\star}$ & & $.015^{\dagger}$ & & $.045^{\star}$ & & $.008^{\dagger}$ \\
\hline Below Matric & 23.63(12.7) & & $6.74(4.6)$ & & $8.63(4.9)$ & & $8.26(5.0)$ & \\
\hline Completed Matric & $26.49(13.7)$ & & $8.34(4.9)$ & & $9.35(5.6)$ & & $8.80(5.1)$ & \\
\hline Tertiary ${ }^{\star}$ & $34.96(10.1)^{*}$ & & $10.88(4.2)^{*}$ & & $11.92(5.2)^{*}$ & & $12.17(3.6)^{\star}$ & \\
\hline Employment* & & $.000^{\ddagger}$ & & $.000^{\ddagger}$ & & $.004^{\dagger}$ & & $.003^{\dagger}$ \\
\hline Employed & $33.63(11.9)^{\star}$ & & $10.95(4.5)^{*}$ & & $11.51(4.3)^{*}$ & & $11.17(4.5)^{\star}$ & \\
\hline Unemployed & $24.34(13.1)$ & & $7.19(4.4)$ & & $8.75(5.5)$ & & $8.40(5.0)$ & \\
\hline Living situation* & & $.001^{\dagger}$ & & $.005^{\dagger}$ & & $.041^{*}$ & & $.000^{\ddagger}$ \\
\hline House $^{\star}$ & $31.98(11.4)^{\star}$ & & $10.04(4.7)^{\star}$ & & $10.82(4.5)^{\star}$ & & $11.12(4.2)^{\star}$ & \\
\hline Nursing Home & $28.41(15.1)$ & & $8.4(4.6)$ & & $10.03(6.1)$ & & $9.97(5.7)$ & \\
\hline Informal dwelling & $20.24(11.8)$ & & $6.38(4.5)$ & & $7.79(5.0)$ & & $6.07(3.9)$ & \\
\hline Level of Injury & & .543 & & .451 & & .328 & & .174 \\
\hline Paraplegia & $27.28(12.4)$ & & $8.92(4.6)$ & & $9.38(4.8)$ & & $8.90(4.5)$ & \\
\hline Quadriplegia & $28.80(14.4)$ & & $8.20(5.2)$ & & $10.38(5.5)$ & & $10.22(5.4)$ & \\
\hline Time Living with SCl & & .065 & & .069 & & .092 & & 073 \\
\hline $1-5$ years & 24.91(11.4) & & $7.56(4.8)$ & & $8.94(4.4)$ & & $8.41(4.5)$ & \\
\hline $6-10$ years & $25.15(14.2)$ & & $8.08(5.3)$ & & $8.31(5.6)$ & & $8.77(4.4)$ & \\
\hline $11-15$ years & $32.76(15.1)$ & & $10.24(4.5)$ & & $11.53(6.1)$ & & $11.00(5.7)$ & \\
\hline 16 and above & $32.54(13.3)$ & & $10.17(4.3)$ & & $11.29(5.4)$ & & $11.08(5.1)$ & \\
\hline
\end{tabular}

Note: SPRS-2, Sydney Psychosocial Scale; OA, Occupational Activities; IR, Interpersonal Relationships; LS, Living Skills.

*Statistically significant at $P<0.05$.

${ }^{\dagger}$ Statistically significant at $\mathrm{P}<0.01$.

‡Statistically significant at $P<0.001$.

included than others. Thus, this may explain the variation on employment rate of our study and the previous one.

Although, the employment rate in this study is higher compared to the one that was previously reported, both employment rates are somewhat lower than the general employment rate in South Africa which is currently at $43.3 \%$. Unemployment is a major challenge affecting persons with disabilities in South Africa. Persons with disabilities are often excluded from employment opportunities due to a number of factors such as discriminatory attitudes, ineffective employment policies, inaccessible and unsupportive work environments and public transportation. As a result, only a few persons with disabilities secure and retain jobs in the open labor markets. ${ }^{19}$ Therefore, rehabilitation professionals and other stakeholders need to continue lobbying for social and political changes that provide employment options for individuals with a TSCI in South Africa in order to improve their psychosocial reintegration.
Individuals living in informal dwellings reported poor psychosocial reintegration compared to those living in formal houses and nursing homes in this study. This is of no surprise because both items "accommodation" and "community travel" are all listed under the living skills domain. Some of the questions asked to participants were " how do you rate your use of transport and travel around the community" and: "how do you rate your living situation" Inaccessible public transport and inaccessible environment are expected to be found in informal dwelling locations. Lack of adequate space in informal dwellings might have contributed negatively on participants' responses to the questions listed under the living skills domain, leading to poor psychosocial reintegration for individuals that were living in informal dwellings.

Lysack et al. ${ }^{20}$ reported that individual perceptions about reintegration may be affected by the community one lives in. This may imply that individuals' perceptions about their living skills in our study might have 
Table 3 The Multivariate regression results for overall SPRS-2 and individual domain scores.

\begin{tabular}{|c|c|c|c|c|c|c|c|c|}
\hline Categories & $\begin{array}{c}\text { SPRS-2 } \\
\text { Standardized } \\
\beta \text { Coefficient }\end{array}$ & $\begin{array}{c}P \\
\text { value }\end{array}$ & $\begin{array}{c}\text { OA } \\
\text { Standardized } \\
\beta \text { Coefficient }\end{array}$ & $\begin{array}{c}P \\
\text { value }\end{array}$ & $\begin{array}{c}\text { IR } \\
\text { Standardized } \\
\beta \text { coefficient }\end{array}$ & $\begin{array}{c}P \\
\text { value }\end{array}$ & $\begin{array}{l}\text { LS } \\
\text { Standardized } \\
\beta \text { Coefficient }\end{array}$ & $\begin{array}{c}P \\
\text { value }\end{array}$ \\
\hline Age Groups & & & & & & & & \\
\hline $\begin{array}{l}\text { 15-30 years } \\
31-45 \text { (Reference) }\end{array}$ & -.115 & .219 & -.130 & .160 & .015 & .882 & -.165 & .078 \\
\hline $\begin{array}{l}46+ \\
\text { Race }\end{array}$ & .132 & .183 & .110 & .262 & .122 & .261 & .119 & .230 \\
\hline $\begin{array}{l}\text { Black } \\
\text { Mixed race(reference) }\end{array}$ & -.113 & .307 & -.116 & .292 & -.131 & .281 & -.054 & .627 \\
\hline $\begin{array}{l}\text { White } \\
\text { Level of education }\end{array}$ & .046 & .657 & .133 & .200 & .038 & .742 & -.046 & .661 \\
\hline $\begin{array}{l}\text { Below Matric } \\
\text { Completed Matric (reference) }\end{array}$ & -.096 & .277 & -.132 & .133 & -.559 & .541 & -.067 & .447 \\
\hline $\begin{array}{l}\text { Tertiary } \\
\text { Employment status }\end{array}$ & .127 & .167 & .082 & .365 & .110 & .275 & .146 & .114 \\
\hline $\begin{array}{l}\text { Employed } \\
\text { Unemployed (reference) } \\
\text { Living situation }\end{array}$ & .258 & $.003^{\dagger}$ & .264 & $.001^{\dagger}$ & .200 & .054 & .190 & $.045^{\star}$ \\
\hline $\begin{array}{l}\text { House } \\
\text { Nursing home (reference) }\end{array}$ & .065 & .543 & .094 & .372 & .020 & .864 & .060 & .570 \\
\hline Informal dwelling & .121 & .303 & -.019 & .872 & -.062 & .632 & -.243 & $.040^{*}$ \\
\hline
\end{tabular}

Note: The reference group is the group that has all dummy variables set to 0. SPRS-2, Sydney Psychosocial Scale; OA, Occupational Activities; IR, Interpersonal Relationships; LS, Living Skills.

*Statistically significant at $P<.05$.

†Statistically significant at $\mathrm{P}<.01$.

been affected by the community and the type of houses they reside in. However, further studies are needed to confirm this hypothesis.

The findings of this study reflect in part the relationship between psychosocial reintegration and social participation and inclusion. Evidence from the literature indicates that housing affects how people interact with others. For example, Hulse et al., ${ }^{21}$ reported that quality of housing can facilitate psychosocial and social outcomes such as ontological security and a sense of control over one's life, as well as integration into local neighborhoods and development of social capital, ultimately contributing to overall societal cohesion. Mallett ${ }^{22}$ also argued that those in poor housing areas and lack of adequate public transport are disadvantaged when it comes to maintaining social ties and friendships. Thus, the home is a base in which people construct their sense of identity, and security, and establish connections with their friends, neighbors and wider community.

\section{Study limitations}

While the data from a sample of adults living with a TSCI in the Cape Metropolitan area include a reasonable representation of racial diversity in South Africa, the sample size was relatively small. Although the results demonstrate the significant positive influence of being employed and negative influence of living in informal dwellings/shacks on psychosocial reintegration, this might not be a true representation of all individuals living with a TSCI in South Africa.

Secondly, our study did not include information about completeness of the levels of injury. This could have influenced the results as persons with incomplete SCI might have a better psychosocial reintegration compared to individuals with complete spinal cord injury. However, none of the injury characteristics were found to be associated with psychosocial reintegration.

The third limitation is that we did not assess preinjury employment status of the participants. Although our main aim was to assess the influence of employment on psychosocial reintegration post TSCI, we recognize this as a limitation to our study after realizing that employment is a strong predictor of psychosocial reintegration after the injury. If we had included pre-injury employment status in our predictor variables, we would have expanded our discussion by comparing the influence of employment on psychosocial integration pre-injury and reintegration post the injury. This would have added strength to our findings.

The fourth limitation is that the questionnaire was sent to participants via email, which might have resulted in recruitment bias as some participants may not have had access to email. 
Lastly, the study was a cross-sectional survey that does not allow the researcher to draw conclusions about the causality between exposures and outcomes.

\section{Implications for practice and policy}

The findings of this study suggest that employment is an important condition for improved psychosocial reintegration. Therefore, there is a need for rehabilitation to focus on addressing barriers and challenges to meaningful occupations including return to work following injury. In the event of a lack of pre-injury work status, a need exists for rehabilitation services to equip persons with a TSCI with skills and abilities to seek work/alternative employment opportunities.

Concerning policy reform, this study highlights the need for more comprehensive rehabilitation services to enable persons with TSCI to overcome environmental challenges linked to employment. In addition, more effort should be made to provide employment opportunities to persons with disabilities as the employment rates are lower in this group compared to the general population. Furthermore, the provision of accessible housing to the person with a TSCI in South Africa is warranted.

\section{Future research}

Future studies should consider the impact of functioning on work status and the effects of pre-injury employment, especially. There is a need to assess the influence of the physical environment and the labor market/ employers hesitancy with respect to employability of persons with $\mathrm{SCI} /$ disability. In addition, there is a need to assess the influence of housing on social inclusion including work participation following a TSCI in South Africa.

\section{Conclusion}

Employment plays a major role in psychosocial reintegration following a TSCI. However, employment rate following a TSCI is still low in South Africa. Therefore, a collaborative effort from different stakeholders including government, private sectors, and non-profit organizations is needed to work together and offer appropriate employment opportunities for individuals with a TSCI. Furthermore, it is evident that individuals living in informal dwellings/shacks experience problems with their living skills. This might be linked to the lack of essential services such as public transport and inaccessible housing in the communities in which they live. Therefore, rehabilitation professionals and policy makers need to continue lobbying for social inclusion and provide accessible housing to persons with a TSCI in order to facilitate their psychosocial reintegration.

\section{Disclaimer statements Contributors None.}

Funding This project was funded by the National Research Foundation of South Africa (NRF). Award no 98727.

Conflicts of interest Authors have no conflict of interests to declare.

\section{ORCID}

Eugene Nizeyimana (1) http://orcid.org/0000-0003-08595013

Joliana Phillips (10) http://orcid.org/0000-0002-7186-8128

Conran Joseph (1) http://orcid.org/0000-0002-3121-2685

\section{References}

1 Molazem Z, Falahati T, Jahanbin I, Ghadakpour S, Jafari P. The effect of psycho-educational interventions on general health of family caregivers of patients with spinal cord injury: A Randomized Controlled Trial. Jundishapur. J Chronic Dis Care 2013;2(4):1-0.

2 Robyn T, Simpson G, Lane-Brown A, Soo C, De Wolf A, Whiting D. Sydney psychosocial reintegration scale (SPRS-2): meeting the challenge of measuring participation in neurological conditions. Aust Psychol 2012;47:20-32.

3 Whiteneck G, Tate D, Charlifue S. Predicting community reintegration after spinal cord injury from demographic and injury characteristics. Arch Physl Med Rehabil 1999;80(11):1485-91.

4 McColl MA, Carlson P, Johnston J, Minnes P, Shue K, Davies D, Karlovits T. The definition of community integration: perspectives of people with brain injuries. Brain Inj 1998;12(1):15-30.

5 Dijkers M. Community integration: conceptual issues and measurement approaches in rehabilitation research. Top Spinal Cord Inj Rehabil 1998;4(1):1-15.

6 Annelies D, Amanda LB, Robyn L, Tate RL, Middleton J, Cameron ID. Measuring community integration after spinal cord injury: validation of the Sydney psychosocial reintegration scale and community integration measure. Qual Life Res 2010; 19(8):1185-93.

7 World Health Organization. International classification of impairments, disabilities, and handicaps: a manual of classification relating to the consequences of disease, published in accordance with resolution WHA29. 35 of the Twenty-ninth World Health Assembly, May 1976. World Health Organization; 1980.

8 World Health Organization. ICIDH-2: International Classification of Impairments, Activities and Participation. A Manual of Dimensions of Disablements and Functioning, Beta-1 Draft for Field Trials. Geneva, WHO. 1997.

9 Hall K, Dijkers M, Whiteneck G, Brooks CA, Krause JS. The Craig handicap assessment and reporting technique (CHART): metric properties and scoring. Top Spinal Cord Inj Rehabil 1998;4(1):16-30.

10 Mudzi W, Stewart A, Musenge E. Community participation of patients 12 months post-stroke in johannesburg, South Africa. Afr J Prim Health Care Fam Med 2013;5(1):1-9.

11 Mothabeng DJ, Eksteen CA, Westaway M. Psychometric validation of the reintegration to normal living index in people living with spinal cord injuries. S Afr J Physiother 2012;68(2):29-32.

12 Rhoda A, Mpofu R, De Weerdt W. Activity limitations of patients with stroke attending out-patient facilities in the Western Cape, South Africa. S Afr J Physiother 2011;67(2):16-22.

13 Buys M. Protecting personal information: implications of the protection of personal information (POPI) Act for healthcare professionals. S Afr Med J 2017;107(11):954-6. 
14 Leach LS, Butterworth P, Strazdins L, Rodgers B, Broom DH, Olesen SC. The limitations of employment as a tool for social inclusion. BMC Public Health 2010;10(1):1-3.

15 Ullah MM, Fossey E, Stuckey R. The meaning of work after spinal cord injury: a scoping review. Spinal Cord 2018;56(2): 92-105.

16 Boschen KA, Tonack M, Gargaro J. Long-term adjustment and community reintegration following spinal cord injury. Int $\mathbf{J}$ Rehabil Res 2003;26(3):157-64.

17 Miller SM. The measurement of self-efficacy in persons with spinal cord injury: psychometric validation of the moorong selfefficacy scale. Disabil Rehabil 2009;31(12):988-93.

18 Post MW, Reinhardt JD, Avellanet M, Escorpizo R, Engkasan JP, Schwegler U, et al. Employment among people with spinal cord injury in 22 countries across the world: results from the international spinal cord injury community survey. Arch Phys Med Rehabil 2020;101(12):2157-66.

19 Lihohla P. Profile of persons with disabilities in South Africa. Census 2011. Statistics South Africa; 2014.

20 Lysack C, Komanecky M, Kabel A, Cross K, Neufeld S. Environmental factors and their role in community integration after spinal cord injury. Can J Occup Ther 2007;74 (3):243-54.

21 Hulse K, Jacobs K, Arthurson K, Spinney A. At home and in place? The role of housing and social inclusion. Australian Housing and Urban Research Institute 2011; 177:1-09.

22 Mallett S. Understanding home: a critical review of the literature. Sociol Rev 2004;52(1):62-89. 